\title{
Development of a Post-Simulation Debriefing Intervention to Prepare Nurses and Nursing Students to Care for Deteriorating Patients
}

Patrick Lavoie, RN, Ph.D. candidate ${ }^{1-3}$

Jacinthe Pepin, RN, Ph.D. ${ }^{1-3}$

Sylvie Cossette, RN, Ph.D. ${ }^{1,3-4}$

${ }^{1}$ Faculty of Nursing, Université de Montréal, C.P. 6128, succ. Centre-Ville, Montreal, QC, Canada, H3C 3J7

${ }^{2}$ Center for Innovation in Nursing Education (CIFI), Faculty of Nursing, Université deMontréal, C.P. 6128, succ. Centre-Ville, Montreal, QC, Canada, H3C 3J7

3 Quebec Nursing Intervention Research Network (RRISIQ), Faculty of Nursing, Université de Montréal, C.P. 6128, succ. Centre-Ville, Montreal, QC, Canada, H3C 3J7

${ }^{4}$ Montreal Heart Institute, 5000 Bélanger Street, Montréal, QC, Canada, H1T 1C8

Corresponding author: Patrick Lavoie, patrick.lavoie.1@umontreal.ca, (514) 343-6111, x34299, C.P. 6128, succ. Centre-Ville, Montreal, QC, Canada, H3C 3J7 


\begin{abstract}
To provide optimal care, nurses need to be prepared to recognize signs and symptoms of patient deterioration so they can obtain assistance from appropriate respondents and initiate rescue interventions when needed. In this paper, we describe the development of a postsimulation educational intervention aimed at improving nurses' and nursing students' recognition and response to patient deterioration. This intervention takes the form of a debriefing after a simulated patient deterioration experience.

Following the Medical Research Council's guidance on complex interventions, we reviewed empirical studies of existing educational interventions for content, teaching strategies, and outcomes, as well as for frameworks, theoretical underpinnings, and rationale. Based on those results, we reviewed theoretical literature (Tanner's clinical judgment model and Dewey's theory of experiential learning) that might inform our understanding of our intervention's intended effect (learning outcomes) and of the mechanisms by which the intervention could lead to it. Integrating results from the empirical and theoretical phases helped us define the new intervention's rationale and develop its components according to relevant standards of best practices. The resulting educational intervention, REsPoND, consists in a reflective debriefing after a patient deterioration simulation. It will be tested in an upcoming mixed methods study.
\end{abstract}




\section{INTRODUCTION}

In the agenda for patient safety, there is a call to improve the quality of care for acutely ill hospitalized patients (Department of Health, 2009; National Institute for Health and Clinical Excellence, 2007; National Patient Safety Agency, 2007a; World Health Organization, 2008). Since McQuillan et al. (1998) evaluated the quality of care prior to admission to intensive care units in the UK, it has been acknowledged that suboptimal care may lead to patients experiencing avoidable adverse events such as intensive care unit admission, cardiac arrest, or death (McGloin et al., 1999; National Confidential Enquiry into Patient Outcome and Death, 2005; National Patient Safety Agency, 2007b).

Suboptimal care has been defined as the "failure to seek and provide appropriate and timely interventions to at risk patients" (Massey et al., 2008). It is linked to failure to recognize cues indicating that a patient is deteriorating (Quirke et al., 2011). Indeed, there is evidence that hospitalized patients are likely to exhibit signs of deterioration in the period preceding adverse events (Buist et al., 2004; Hodgetts et al., 2002; Kause et al., 2004). The National Institute for Health and Clinical Excellence (2007) recommended that tools to recognize deterioration take into account a set of objective and quantifiable indicators that refer to disturbances in physiological parameters. These recommendations were reiterated by the Royal College of Physicians (2012), and objective signs are typically included in early warning scores and other track and trigger systems (Smith et al., 2008a; Smith et al., 2008b). Additionally, nurses may identify patients at risk for adverse events by using non-quantifiable criteria such as respiratory, circulatory, neurological, or other symptoms (Cioffi et al., 2009; Gazarian et al., 2010). The subjective 'worried' criterion has been cited by nurses as the most frequent reason for seeking help for a deteriorating patient (Santiano et al., 2009). 
Whatever the nature of these cues, nurses are expected to recognize them promptly so they can obtain assistance from appropriate respondents and initiate rescue interventions when needed (Department of Health, 2009; Odell et al., 2009). Nevertheless, nurses do not always monitor, document, or act upon these signs; this has been identified as a contributing factor in the failure to recognize patient deterioration (Ludikhuize et al., 2012; McQuillan et al., 1998; Odell et al., 2009; Tirkkonen et al., 2013). When track and trigger systems are available, research has shown that nurses do not use these tools in a consistent manner (Donohue et al., 2010).

Therefore, there is consensus on the need to improve nurses' ability to assess and recognize signs and symptoms indicating that a patient is deteriorating, so they can respond promptly and appropriately (Department of Health, 2009; Liaw et al., 2011b; Odell et al., 2009). Nursing educators must answer the call by developing educational interventions that will enhance nurses' and nursing students' ability to recognize signs and symptoms and respond adequately in patient deterioration situations. This paper reports on the development of such an educational intervention, using the Medical Research Council (2008) guidance on complex interventions. This intervention takes the form of a debriefing after a simulated patient deterioration experience. It is based on theoretical and empirical knowledge from a clinical judgment model (Tanner, 2006), an experiential learning theory (Dewey, 1909/2007, 1938/1997), and standards of best practice regarding post-simulation debriefing (Decker et al., 2013).

\section{METHODS}

According to the Medical Research Council (2008), interventions are complex when they consist of several interacting components, can be tailored, and require multiple and skilled behaviors from deliverers and recipients. The model describes how such an intervention should be developed, piloted for feasibility, evaluated, and implemented. In this paper, we report on the first of those steps. 
The development step involves three interlinked phases: 1) identification of the evidence base for the intervention, 2) identification of an appropriate theory, and 3) modeling of the intervention's processes and outcomes. For the intervention reported here, a literature review on existing educational interventions to prepare nurses or nursing students for patient deterioration situations informed both phase 1 and phase 2. This review addressed the content of existing interventions; their teaching strategies; their frameworks, theoretical underpinnings, or rationale; and their outcomes. Phase 2 continued with the exploration of additional theoretical literature that could orient the understanding of the intervention's intended effect, namely to improve nurses' ability to identify and intervene in patient deterioration situations. Examination of learning theories that could explain mechanisms by which the intervention could lead to such learning outcomes was also part of phase 2. Finally, in phase 3, the integration of results from phase 1 and 2 allowed for definition of the intervention's theory, and relevant standards of best practice to make explicit the intervention's specific components.

\section{PHASE 1: REVIEWING EXISTING INTERVENTIONS}

Database search resulted in 19 primary papers published from 2002 to 2012 on existing educational interventions aimed at preparing nurses to recognize and respond to patient deterioration situations (detailed in Table 1). There were also two literature reviews (Fisher and King, 2013; Liaw et al., 2011b) that covered parts of this literature.

The content of those interventions mainly revolved around assessment and intervention. Authors suggested a systematic approach to patient assessment (Gordon and Buckley, 2009), sometimes using the $\mathrm{ABCDE}$ mnemonic (airway, breathing, circulation, disorder, environment or exposure) (Fuhrmann et al., 2009; Gallagher and Traynor, 2012; Lewis, 2011; Liaw et al., 2011a; Smith et al., 2002), along with vital signs measurement (Mitchell et al., 2010). Such approaches are expected to help in recognizing signs and symptoms of deterioration, so they can be acted on 
with appropriate interventions. These interventions are defined according to best practices or clinical guidelines, such as algorithms from different healthcare organizations.

Other topics addressed in the reviewed interventions are communication and teamwork. The SBAR mnemonic (situation, background, assessment, recommendation) is proposed as a way to structure communication efficiently (Fuhrmann et al., 2009; Jacobson et al., 2010; Liaw et al., 2011a; Mitchell et al., 2010). Other teamwork abilities discussed appear to be inspired by nontechnical skills in crisis management (Fletcher et al., 2002; Gaba et al., 1994). In some cases, the pathophysiology of clinical conditions associated with deterioration is also part of the educational interventions (Liaw et al., 2011a; Perkins and Kisiel, 2013).

This content is presented through an array of teaching strategies-reading, lectures, case studies, problem-based learning, skills practice - the most frequent strategy being simulation, with or without debriefing. In fact, all reviewed interventions involved at least one form of simulation, from low- to high-fidelity and from computer- to mannequin-based. The main argument for using simulation as a teaching strategy is that it exposes learners to rare clinical events in a realistic manner (Buykx et al., 2011; Fuhrmann et al., 2009; Lewis, 2011; Rice et al., 2009; Tait et al., 2008; Unsworth et al., 2012; Wehbe-Janek et al., 2012). It also represents a safe environment, where learners can make mistakes without threatening a real patient's safety (Fuhrmann et al., 2009; Schubert, 2012; Tait et al., 2008).

Nevertheless, authors rarely propose a theoretical understanding of how simulation can lead to learning outcomes. It is said to be aligned with adult learners' needs (Knowles et al., 2011), because it is an active, participatory, and experiential teaching strategy (Fuhrmann et al., 2009; Hoffman et al., 2011; Smith et al., 2002). However, experiential learning theories state that reflection on an experience is necessary for learning (Boud, Keogh, \& Walker, 1995; Dewey, 1909/2007; Kolb, 1984). In the context of simulation, reflection occurs during debriefing, which 
follows most simulation exercises (Fanning and Gaba, 2007). Despite the importance of debriefing, there are few accounts of how it is conducted. When debriefing is addressed, it is described as an opportunity for learners to identify, by themselves or with the feedback of a trainer, strengths and weaknesses in their actions and those of their peers during the simulation, so they can identify ways to improve their performance in future similar experiences (Buykx et al., 2011; Schubert, 2012; Smith et al., 2002; Unsworth et al., 2012; Wehbe-Janek et al., 2012). In these contexts, debriefings appear more as performance assessments than as exercises in reflection. Thus, there seems to be a tacit postulate that exposure to a simulated clinical event will result in learning, since it is a training opportunity for skills in recognizing and responding to patient deterioration.

Most of these studies showed an increase in subjective self-assessments such as level of confidence, of knowledge, or of skills (Buckley and Gordon, 2011; Buykx et al., 2012; Featherstone et al., 2005; Fuhrmann et al., 2009; Gallagher and Traynor, 2012; Hoffman et al., 2011; Jacobson et al., 2010; Lewis, 2011; Perkins and Kisiel, 2013; Unsworth et al., 2012; Wehbe-Janek et al., 2012). Because of this, the interventions were perceived as useful and participants were satisfied with them (Buykx et al., 2012; Fuhrmann et al., 2009; Hoffman et al., 2011; Rice et al., 2009; Tait et al., 2008). Few studies used more objective assessments. One of these showed improvement in knowledge and critical thinking scores (Schubert, 2012). Three studies evaluated performance and clinical outcomes (Buykx et al., 2012; Liaw et al., 2011a; Mitchell et al., 2010). The RAPIDS program (Liaw et al., 2011a) was followed by improvement in assessment, management, and communication in patient deterioration situations. A second multifaceted intervention (Mitchell et al., 2010) resulted in reduced avoidable adverse events (unplanned intensive care unit admission and unexpected death) and increased medical emergency team reviews and vital signs documentation; besides its educational component, the 
intervention's components included a change in an observation chart and introduction of a track and trigger system. The third educational program (Buykx et al., 2012; Buykx et al., 2011) showed an increase in observation and pain score recordings, as well as correct application of oxygen therapy. Although these outcomes are desirable, there is still a lack of knowledge as to how the educational interventions led to these outcomes.

In summary, the reviewed educational interventions mostly focused on assessment of patients to recognize when they are deteriorating. Because nursing interventions depend on a patient's clinical condition, nurses need to be prepared to understand what is going on with patients, beyond the fact that they are deteriorating. By putting learners in a realistic and safe encounter with a deteriorating patient, simulation serves as a potent teaching strategy. Nevertheless, investigations of theoretical underpinnings, namely experiential learning theories, are still needed to expand our understanding of the effectiveness of simulation-based educational interventions.

\section{PHASE 2: IDENTIFYING APPROPRIATE THEORY}

Some interventions reviewed in the first phase addressed the theoretical and procedural contents, i.e., learning material to be further assimilated through simulation exercises, while others consisted only in the simulation exercise itself. Since the intervention was to be integrated into and tested in the context of a critical care course for which content was already established, the focus of the work presented here shifted to developing an effective simulation-based educational intervention. Because its aim was to improve nurses' performance in recognizing and responding to patient deterioration, a clinical judgment model (Tanner, 2006) that depicts how nurses decide what is to be done in a particular patient's situation became relevant. An experiential learning theory (Dewey, 1909/2007, 1938/1997) provided a model of the process by which learning outcomes were to be attained.

\section{Clinical judgment model}


Tanner's (2006) clinical judgment model, based on a synthesis of nearly 200 studies, depicts nurses' decision-making process. According to the model, nurses notice elements in a clinical situation that demand attention, interpret them, and develop an understanding of the situation so they can respond with actions they deem appropriate. Noticing depends on the nurses' assessment of the situation and their expectations regarding it. Expectations arise from individual knowledge of a patient, knowledge of patients with similar health experiences, and formal knowledge. Clinical judgment occurs between interpretation of the data and the nurse's response. In other words, clinical judgment happens when nurses reach a conclusion on the patient's needs based on their interpretation of the data and decide on an action plan. As they execute this plan, they adjust their interventions according to the patient's response (reflection-in-action). Afterwards, they review the whole process in light of its results (reflection-on-action), so clinical learning can happen.

In the context of patient deterioration, nurses need to notice and interpret signs of deterioration, so they can understand why the patient is deteriorating. They can then decide on an action plan to respond appropriately and prevent further deterioration. Although Tanner (2006) identified reflection-on-action as the cornerstone of clinical judgment development, she observed that literature linking clinical judgment and reflection is scant. However, she credited Dewey (1909/2007) with developing the latter concept in his theory of experiential learning.

\section{Experiential learning theory}

In Dewey's experiential learning theory (1938/1997), experience is both the source and the product of learning. The concept is defined as a reciprocal transaction between the "organism" (i.e., the human being) and its environment, where action of the former influences the objective conditions of the latter and vice-versa. This relationship is adaptive because the organism seeks to adapt itself to environmental conditions to achieve its own ends. 
To reach these ends or consequences, the organism actively perceives a set of environmental conditions. These conditions may or may not already be connected to patterns of action or response, which are known to produce certain consequences. When such a connection is already established, the organism chooses a pattern of action that seems appropriate to attain the desired end (Dewey, 1930). In this case, the situation is determinate and therefore, unproblematic.

A situation is indeterminate when the organism, in regard to the conditions at hand, does not know which actions are appropriate to get to an intended end. An indeterminate situation also occurs when beliefs about an object are incompatible with what is observed of that object or when an event or a behavior cannot be explained with what is already known in terms of wellestablished laws. In all these cases, the situation generates a feeling of doubt or uncertainty, which makes it problematic and triggers reflection (Dewey, 1909/2007). Reflection comprises five steps: 1) occurrence of a problematic situation; 2) deliberate observation of environmental conditions to define the problem; 3) inference of a possible suggestion or hypothesis; 4) rational elaboration of the suggestion in light of its implications; and 5) corroboration of the suggestion by experimenting and comparing actual consequences to those anticipated (Dewey, 1909/2007, 1922). It involves both integrating fragmented data to arrive at an understanding of their meaning (induction) and fleshing out the full implications of that meaning and its possible consequences (deduction).

Through this process, scattered environmental conditions are organized into a coherent whole that evokes a particular response, which constitutes the meaning of the situation. By understanding the meaning of a situation, the organism can better differentiate the environment and form appropriate habits. Differentiation happens when a set of environmental conditions becomes coherent and perceptible, and likely to draw the attention of the organism in the future. Habits, defined as predispositions to act in a certain manner, form when a mode of response has 
been judged properly adaptive to the organism's environmental conditions, i.e., when its ends have been achieved.

In the educational context, Dewey (1938/1997) promoted experience as a vector for learning. Learning opportunities are created based on the educator's own learning experiences, by adjusting objective conditions of the learners' environment. Through reflection on a learning experience, the learner can reconstruct it and thereby understand its meaning.

The results of phase 2, combined with those of phase 1, informed the development of the simulation-based educational intervention. According to experiential learning theory (Dewey, 1909/2007), reflection on an indeterminate and problematic situation is necessary for learning. Therefore, if a patient deterioration simulation is perceived as problematic, reflection during the debriefing becomes the keystone of simulation-based learning. Nevertheless, although debriefing was described as the most important component of simulation in the literature (McGaghie et al., 2010), there were few accounts of how to conduct it in the papers reviewed in phase 1 . Thus, the development of the debriefing after a patient deterioration simulation became the focus of this work. Debriefing can be defined as "the process whereby faculty and students re-examine the clinical encounter" (Dreifuerst, 2009) and as a "facilitated or guided reflection in the cycle of experiential learning" (Fanning and Gaba, 2007).

\section{PHASE 3: MODELING PROCESS AND OUTCOMES}

\section{Defining the intervention's process}

This educational intervention is named "Reflective dEbriefing after a PatieNt Deterioration simulation" (REsPoND). It is a debriefing model that is to be used after a group of learners have participated in a simulated patient deterioration scenario. Prior to their participation in the simulation, learners receive a pre-briefing on what to expect in the simulation environment. This will be discussed further below. 
In REsPoND's theory, illustrated in Figure 1, the simulation is conceptualized as a learning experience wherein nurses or nursing students encounter simulated environmental conditions. These conditions are realistically presented to a group of learners, using a high-fidelity mannequin exhibiting signs and symptoms of patient deterioration. Given the scenario's complex nature and previous experiences with simulations of patient deterioration (Lavoie, Pepin, \& Boyer, 2013), it is anticipated that learners will consider this experience problematic. Thus, it becomes an opportunity for them to understand the meaning of the situation, improve their differentiation of the environment, and form effective habits regarding deteriorating patients.

REsPoND begins with a facilitator asking the group of learners about their feelings regarding the simulation. This is meant partly to acknowledge their experience of the simulation and allow emotional release (Dreifuerst, 2009), but mostly to establish the problematic nature of the simulated situation. Once this is done, the facilitator guides reconstruction of the experience through questions, presented in Table 2, following Dewey's $(1909 / 2007,1922)$ reflective steps.

The reflective questions in REsPoND parallel Tanner's model of clinical judgment (2006) and are presented within frameworks that are known to the learners. Of these frameworks, the primary and secondary trauma survey (Emergency Nurses Association, 2007) structures the second step of the reflective process because of its congruence with the ABCDE mnemonic used in previous studies. Moreover, an evidence-based list of signs of deterioration assists learners in discriminating between relevant and irrelevant data in the simulated experience.

\section{Defining the expected learning outcomes}

REsPoND aims at preparing nurses and nursing students to manage patient deterioration situations. It consists in a post-simulation debriefing where learners are guided through a reflection on a simulated experience of patient deterioration. The intervention is expected to lead to an understanding of the meaning of such a situation. Accordingly, REsPoND's purposes are 1) 
to improve participants' ability to perceive and notice clinical signs of deterioration (differentiation) and 2) to facilitate integration of relevant interventions or responses regarding these symptoms into their practice (habit formation).

\section{Defining the intervention's components}

A high-fidelity patient deterioration simulation precedes REsPoND. Before experiencing the simulated scenario, participants are given the simulated patient's chart as pre-reading material so they can assimilate the patient's health history. The simulation scenario follows three phases. In the initial phase, they are expected to assess the simulated patient, who is stable with mild alteration of vital signs and symptoms of early deterioration. Next, in the deterioration phase, the patient's vital signs deteriorate rapidly and the patient exhibits respiratory, cardiovascular, or neurological symptoms indicating progression towards critical illness. If participants recognize these symptoms appropriately and act accordingly, the scenario evolves to the recovery phase, where vital signs stabilize and symptoms are managed. Examples of patient deterioration scenarios that can precede REsPoND are: pulmonary edema, cardiogenic shock, and sepsis, to name a few.

Standards of best practice regarding the debriefing process, recently published by the International Nursing Association for Clinical Simulation and Learning (INACSL) (Decker et al., 2013) defined REsPoND's components. These standards specify that debriefing should be conducted in a safe environment for learning (Decker et al., 2013). Many means for achieving this are suggested in the literature, but the most frequently cited are presenting the learning activity objectives, establishing a confidentiality contract, and agreeing to ground rules for respect between participants (Decker, 2007; Fanning and Gaba, 2007; Flanagan, 2008; Neill and Wotton, 2011; Rudolph et al., 2006; Rudolph et al., 2008; Wickers, 2010). Hence, REsPoND includes a pre-brief session (Fanning and Gaba, 2007), in which a facilitator explains the 
functioning of the simulation-debriefing learning activity and its goals, purposes, and rules. If it is the participants' first contact with the simulation environment, they are given an orientation on the setting, the equipment, and the mannequin's functions. Afterwards, the facilitator establishes a contract of confidentiality with the participants to cover the simulation and the debriefing. The participants are advised that error is allowed in the simulated experience and that they should remain respectful of each other at all times. Additionally, the facilitator ensures a safe environment by treating participants in a non-threatening manner (Decker et al., 2013; Neill and Wotton, 2011; Waxman, 2010).

According to INACSL's standards, the debriefing should be facilitated by someone trained and competent in the debriefing process who has witnessed the simulated experience (Decker et al., 2013). The facilitator acts as a co-learner, guiding the discussion during debriefing rather than teaching (Fanning and Gaba, 2007; Flanagan, 2008). Verbal and non-verbal forms of communication are used to stimulate participation and nurture the reflective process (Decker, 2007; Fanning and Gaba, 2007). In REsPoND, the facilitator also has to master the clinical content of the simulation's scenario, whether from expertise or from thorough study of the content. The facilitator uses a series of open-ended questions to guide the reflective process. These questions are derived from the clinical judgment model (Tanner, 2006) and Dewey's (1909/2007, 1922) depiction of the reflective process. Grounding the questions in theoretical frameworks also follows another INACSL standard, which is that the content of debriefing should be defined based on a structured framework (Decker et al., 2013). These questions are to be adapted by the facilitator according to the evolution of the debriefing process.

Other issues addressed in INACSL standards are video assistance and timing of the debriefing (Decker et al., 2013). Although video playback of the simulation has been proposed to facilitate recollection of a simulation (Flanagan, 2008), research on debriefing has not shown significant 
differences between cases where it was used and those where it was not (Savoldelli et al., 2006; Sawyer et al., 2012). Accordingly, from the outset video assistance was not included as a component of REsPoND. As for timing, research has shown that participants tend to prefer debriefing immediately after the simulation (Cantrell, 2008; Neill and Wotton, 2011; Waxman, 2010). Sufficient time should be allowed to fulfill the objectives of the debriefing session (Decker et al., 2013). Therefore the duration of REsPoND's components can be customized to suit the content and overall duration of the intervention.

Although it is not part of INACSL standards, authors recommend that debriefing be conducted in a room other than the one where simulation took place, to reduce tension and provide a setting that promotes reflection (Fanning and Gaba, 2007; Waxman, 2010). Participants should gather in a circle with the facilitator (Decker, 2007; Steinwachs, 1992; Wickers, 2010). These aspects are included in REsPoND's components.

\section{DISCUSSION}

This paper presented the development of a complex educational intervention for preparing nurses and nursing students to manage patient deterioration situations. These findings suggest that defining this interaction through a clinical judgment model (Tanner, 2006) helps clarify the intervention's objective and expected outcomes. Dewey's (1909/2007, 1938/1997) experiential learning theory contributes to understanding how a reflective debriefing after a simulated patient deterioration experience can produce these outcomes. Standards of best practice for debriefing (Decker et al., 2013) and empirical evidence suggest means to improve the intervention's effectiveness.

Defining REsPoND's aim and outcomes through those theories supports educational efforts for improving nurses and nursing students' assessment and intervention skills. Their interventions depend on their clinical judgment - the understanding of a situation they develop based on 
assessment data. Therefore, nurses and nursing students need to integrate comprehensive assessment skills into their practice so they can notice relevant signs promptly. Nevertheless, it seems insufficient to teach systematic approaches to assessment, since noticing important elements of a situation depends on expectations regarding the situation. A potent strategy to shape nurses and nursing students' expectations might be to generate meaning for patient deterioration situations through the inductive and deductive movements of the reflective process.

In contrast to comparable interventions, REsPoND emphasizes the role of experience and the importance of reflection in learning. Some interventions (Beattie et al., 2010; Dreifuerst, 2012; Kriz, 2010), based on a learner-centered paradigm (Fink, 2003), tend to define learning as an internal process promoted by active involvement in a meaningful learning experience. In such cases, debriefing consists of participants sharing perspectives on the events in a simulation, and learning objectives emerge through the discussion. In REsPoND, learning objectives are predefined, and participants are invited to reflect on a simulated experience in a structured manner.

Alternatively, some debriefings (Chronister and Brown, 2012; Rudolph et al., 2006; Rudolph et al., 2008) are based on closing gaps between participants' actual and expected knowledge and performance, as defined by external standards (e.g. crisis management in anesthesia, cardiopulmonary resuscitation guidelines). There are also debriefings that focus on cognitive rehearsal of nurses' decision-making process (Hoffman et al., 2011; Kuiper et al., 2008). Others are based on the application of concepts from conceptual models or other nursing frameworks (Decker, 2007; Lusk and Fater, 2013; McClure and Gigliotti, 2012). In all these cases, learning is defined as the transmission of external knowledge or as the internalization of a process to apprehend an external reality. REsPoND is based on the idea that learners are able to understand the meaning of a patient deterioration situation by being guided through a reflective process. 
External knowledge becomes a means to facilitate this understanding and to frame learners' new conceptualizations, rather than being a learning objective in itself.

In REsPoND, knowledge and learning come from the learner's experience of the environment. Reflecting on what happened during the event helps the learner elucidate the meaning of the situation. In this transactional ontology, meaning is understood as a connection between external conditions and the end desired by the individual, and is expressed in the actions taken with respect to external conditions to achieve that desired end. In this sense, this proposal is closer to other experience-focused conceptions of the debriefing process (Cant and Cooper, 2011; Decker, 2007; Parker and Myrick, 2010), where current learning is integrated with previous knowledge to influence future experiences. However, this paper puts forth a thorough operationalization of the reflective process and its grounds, which is not always as clear in other proposals.

Although based on existing knowledge on assessment of and intervention with deteriorating patients, this work represents a contribution to intervention development research in the field of simulation-based teaching and learning in nursing. One reason for this is our use of a complex intervention development framework (Medical Research Council, 2008). (Paragraph removed) This framework entails the development of a theoretical understanding of how an intervention will result in the desired outcomes. As pointed out in the review of existing interventions in the first phase, most descriptions of educational interventions for preparing nurses and nursing students to manage patient deterioration situations do not explain the processes by which they produce their expected learning outcomes. This was also noted as a weakness in the debriefing literature (Raemer et al., 2011), and it has been observed that further research is needed to understand how debriefing contributes to learning in simulation-based teaching (Neill and Wotton, 2011). Although this intervention proposal is still at a theoretical level, it offers a plausible explanation of this phenomenon that warrants testing in future studies. 
It is also important to note that the standards of best practice upon which it relies do not disclose the level of evidence supporting them. An examination of the literature on debriefing shows that certain claims regarding best practices remain at a theoretical level, without empirical evidence to back them up. Research is needed to address these postulates.

\section{CONCLUSION}

An educational intervention, REsPoND, resulted from work following the Medical Research Council (2008) guidance on complex intervention development and evaluation. Through postsimulation debriefing consisting of guided reflection on a simulated patient deterioration experience, REsPoND aims at improving nurses' and nursing students' perception of signs of deterioration so they can respond appropriately. REsPoND's effect is to be evaluated in an upcoming randomized controlled trial that will also qualitatively explore the process by which the effect is achieved.

\section{REFERENCES}

Beattie, B., Koroll, D., Price, S., 2010. Designing nursing simulation clinical experiences to promote critical inquiry. College Quarterly 13.

Boud, D., Keogh, R., Walker, D., 1985. Promoting reflection in learning: A model, in: Boud, D., Keogh, R., Walker, D. (Eds.), Reflection: Turning experience into learning, New York, NY, pp. 18-40.

Buckley, T., Gordon, C., 2011. The effectiveness of high fidelity simulation on medical-surgical registered nurses' ability to recognise and respond to clinical emergencies. Nurse Education Today 31, 716-721.

Buist, M., Bernard, S., Nguyen, T.V., Moore, G., Anderson, J., 2004. Association between clinically abnormal observations and subsequent in-hospital mortality: A prospective study. Resuscitation 62, 137-141.

Buykx, P., Cooper, S., Kinsman, L., Endacott, R., Scholes, J., McConnell-Henry, T., Cant, R., 2012. Patient deterioration simulation experiences: Impact on teaching and learning.

Collegian 19, 125-129. 
Buykx, P., Kinsman, L., Cooper, S., McConnell-Henry, T., Cant, R., Endacott, R., Scholes, J., 2011. FIRST2ACT: Educating nurses to identify patient deterioration - A theory-based model for best practice simulation education. Nurse Education Today 31, 687-693.

Cant, R.P., Cooper, S.J., 2011. The benefits of debriefing as formative feedback in nurse education. Australian Journal of Advanced Nursing 29, 37-47.

Cantrell, M.A., 2008. The Importance of debriefing in clinical simulations. Clinical Simulation in Nursing 4, e19-23.

Chronister, C., Brown, D., 2012. Comparison of simulation debriefing methods. Clinical Simulation in Nursing 8, e281-288.

Cioffi, J., Conway, R., Everist, L., Scott, J., Senior, J., 2009. 'Patients of concern' to nurses in acute care settings: A descriptive study. Australian Critical Care 22, 178-186.

Decker, S., 2007. Integrating guided reflection into learning experiences, in: Jeffries, P.R. (Ed.), Simulation in nursing education: From conceptualization to evaluation. National League for Nursing, New York, NY, pp. 73-89.

Decker, S., Fey, M., Sideras, S., Caballero, S., Rockstraw, L., Boese, T., Franklin, A.E., Gloe, D., Lioce, L., Sando, C.R., Meakim, C., Borum, J.C., 2013. Standards of best practice: Simulation standard VI: The debriefing process. Clinical Simulation in Nursing 9, S26-29.

Department of Health, 2009. Competencies for recognising and responding to acutely ill patients in hospital. Her Majesty's Stationery Office, London.

Dewey, J., 1922. An analysis of reflective thought. The Journal of Philosophy 19, 29-38.

Dewey, J., 1930. Conduct and experience, in: Murchison, C. (Ed.), Psychologies of 1930: International university series in psychology. Clark University Press, Worcester, MA, pp. 409-422.

Dewey, J., 1997. Experience and education. Touchstone, New York, NY.

Dewey, J., 2007. How we think. Digireads.com, Stilwel, KS.

Donohue, L.A., Endacott, R., 2010. Track, trigger and teamwork: communication of deterioration in acute medical and surgical wards. Intensive \& Critical Care Nursing 26, 10-17.

Dreifuerst, K.T., 2009. The essentials of debriefing in simulation learning: A concept analysis. Nursing Education Perspectives 30, 109-114.

Dreifuerst, K.T., 2012. Using debriefing for meaningful learning to foster development of clinical reasoning in simulation. Journal of Nursing Education 51, 326-333.

Emergency Nurses Association, 2007. Trauma nursing core course (TNCC) provider manual, 6 ed. Emergency Nurses Association, Des Plaines, IL. 
Fanning, R.M., Gaba, D.M., 2007. The role of debriefing in simulation-based learning. Simulation in Healthcare 2, 115-125.

Featherstone, P., Smith, G.B., Linnell, M., Easton, S., Osgood, V.M., 2005. Impact of a one-day inter-professional course (ALERT) on attitudes and confidence in managing critically ill adult patients. Resuscitation 65, 329-336.

Fink, L.D., 2003. Creating significant learning experiences. Jossey-Bass, San Francisco, CA.

Fisher, D., King, L., 2013. An integrative literature review on preparing nursing students through simulation to recognize and respond to the deteriorating patient. Journal of Advanced Nursing 69, 2375-2388.

Flanagan, B., 2008. Debriefing: Theory and techniques, in: Riley, R.H. (Ed.), Manual for simulation in healthcare. Oxford University Press, Hew York, NY, pp. 156-170.

Fletcher, G.C.L., McGeorge, P., Flin, R.H., Glavin, R.J., Maran, N.J., 2002. The role of nontechnical skills in anaesthesia: A review of current literature. British Journal of Anaesthesia 88, 418-429.

Fuhrmann, L., Ostergaard, D., Lippert, A., Perner, A., 2009. A multi-professional full-scale simulation course in the recognition and management of deteriorating hospital patients. Resuscitation 80, 669-673.

Gaba, D.M., Fish, K.J., Howard, S.K., 1994. Crisis management in anesthesiology. Churchill Linvingstone, Philadelphia, PA.

Gallagher, P., Traynor, M., 2012. Does an Immediate Life Support (ILS) course enhance clinical practice? The students' perceptions. Nurse Education Today 32, 594-599.

Gazarian, P.K., Henneman, E.A., Chandler, G.E., 2010. Nurse decision making in the prearrest period. Clinical nursing research 19, 21-37.

Gordon, C.J., Buckley, T., 2009. The effect of high-fidelity simulation training on medicalsurgical graduate nurses' perceived ability to respond to patient clinical emergencies. Journal of Continuing Education in Nursing 40, 491-500.

Hodgetts, T.J., Kenward, G., Vlackonikolis, I., Payne, S., Castle, N., Crouch, R., Ineson, N., Shaikh, L., 2002. Incidence, location and reasons for avoidable in-hospital cardiac arrest in a district general hospital. Resuscitation 54, 115-123.

Hoffman, K., Dempsey, J., Levett-Jones, T., Noble, D., Hickey, N., Jeong, S., Hunter, S., Norton, C., 2011. The design and implementation of an Interactive Computerised Decision Support Framework (ICDSF) as a strategy to improve nursing students' clinical reasoning skills. Nurse Education Today 31, 587-594. 
Jacobson, T., Belcher, E., Sarr, B., Riutta, E., Ferrier, J.D., Botten, M.A., 2010. Clinical scenarios: Enhancing the skill set of the nurse as a vigilant guardian. Journal of Continuing Education in Nursing 41, 347-353.

Kause, A., Smith, G., Prytherch, D., Parr, M., Falbouris, A., Hillman, K., 2004. A comparison of Antecedents to Cardiac Arrests, Deaths, and EMergency Intensive care Admissions in Australia and New Zealand, and the United Kingdom - The ACADEMIA study. Resuscitation 62, 275-282.

Knowles, M.S., Holton, E.F., Swanson, R.A., 2011. The adult learner: The definitive classic in adult education and human resource development, 7 ed. Elsevier, Amsterdam.

Kolb, D.A., 1984. Experiential learning: Experience as the source of learning and development. Prentice-Hall, Englewood Cliffs, NJ.

Kriz, W.C., 2010. A systemic-constructivist approach to the facilitation and debriefing of simulations and games. Simulation \& Gaming 41, 663-680.

Kuiper, R., Heinrich, C., Matthias, A., Graham, M.J., Bell-Kotwall, L., 2008. Debriefing with the OPT model of clinical reasoning during high fidelity patient simulation. International journal of nursing education scholarship 5, Article17.

Lavoie, P., Pepin, J., Boyer, L., 2013. Reflective debriefing to promote novice nurses' clinical judgment after high-fidelity clinical simulation: A pilot test. Dynamics 24(4), 36-41.

Lewis, R., 2011. Learning the 'SMART' way: Results from a pilot study evaluating an interprofessional acute care study day. Nurse Education Today 31, 88-93.

Liaw, S.Y., Rethans, J.J., Scherpbier, A., Piyanee, K.Y., 2011a. Rescuing A Patient In Deteriorating Situations (RAPIDS): A simulation-based educational program on recognizing, responding and reporting of physiological signs of deterioration. Resuscitation $82,1224-1230$.

Liaw, S.Y., Scherpbier, A., Klainin-Yobas, P., Rethans, J.J., 2011b. A review of education strategies to improve nurses' roles in recognizing and responding to deteriorating patients. International Nursing Review 58, 296-303.

Ludikhuize, J., Smorenburg, S.M., de Rooij, S.E., de Jonge, E., 2012. Identification of deteriorating patients on general wards: Measurement of vital parameters and potential effectiveness of the Modified Early Warning Score. Journal of Critical Care 27, 424.e427424.e413.

Lusk, J.M., Fater, K., 2013. Postsimulation debriefing to maximize clinical judgment development. Nurse educator 38, 16-19.

Massey, D., Aitken, L.M., Wendy, C., 2008. What factors influence suboptimal ward care in the acutely ill ward patient? Australian Critical Care 21, 127-140. 
McClure, M., Gigliotti, E., 2012. A medieval metaphor to aid use of the Neuman systems model in simulation debriefing. Nursing Science Quarterly 25, 318-324.

McGaghie, W.C., Issenberg, S.B., Petrusa, E.R., Scalese, R.J., 2010. A critical review of simulation-based medical education research: 2003-2009. Medical Education 44, 50-63.

McGloin, H., Adam, S., Singer, M., 1999. Unexpected deaths and referrals to intensive care of patients on general wards. Are some cases potentially avoidable? Journal of the Royal College of Physicians London 33, 255-259.

McQuillan, P., Pilkington, S., Allan, A., Taylor, B., Short, S., Morgan, G., Nielsen, M., Barrett, D., Smith, G., 1998. Confidential inquiry into quality of care before admission to intensive care. British Medical Journal 316, 1853-1858.

Medical Research Council, 2008. Developing and evaluating complex interventions: New guidance. Medical Research Council, London.

Mitchell, I.A., McKay, H., Van Leuvan, C., Berry, R., McCutcheon, C., Avard, B., Slater, N., Neeman, T., Lamberth, P., 2010. A prospective controlled trial of the effect of a multifaceted intervention on early recognition and intervention in deteriorating hospital patients. Resuscitation 81, 658-666.

National Confidential Enquiry into Patient Outcome and Death, 2005. An acute problem? NCEPOD, London.

National Institute for Health and Clinical Excellence, 2007. Acutely ill patients in hospital: recognition of and response to acute illness in hospital. National Institute for Health and Clinical Excellence, London, UK.

National Patient Safety Agency, 2007a. Recognising and responding appropriately to early signs of deterioration in hospitalized patients. NPSA, London, UK.

National Patient Safety Agency, 2007b. Safer care for the acutely ill patient: Learning from serious incidents. National Patient Safety Agency, London, UK.

Neill, M.A., Wotton, K., 2011. High-fidelity simulation debriefing in nursing education: A literature review. Clinical Simulation in Nursing 7, e161-168.

Odell, M., Victor, C., Oliver, D., 2009. Nurses' role in detecting deterioration in ward patients: systematic literature review. Journal of Advanced Nursing 65, 1992-2006.

Parker, B., Myrick, F., 2010. Transformative learning as a context for human patient simulation. Journal of Nursing Education 49, 326-332.

Perkins, C., Kisiel, M., 2013. Developing the recognition and response skills of student nurses. British Journal of Nursing 22, 715-724. 
Quirke, S., Coombs, M., McEldowney, R., 2011. Suboptimal care of the acutely unwell ward patient: A concept analysis. Journal of Advanced Nursing 67, 1834-1845.

Raemer, D., Anderson, M., Cheng, A., Fanning, R., Nadkarni, V., Savoldelli, G., 2011. Research regarding debriefing as part of the learning process. Simulation in Healthcare: The Journal of The Society for Medical Simulation 6, S52-57.

Rice, B., Gallagher, P., Mc Kenna, N., Traynor, M., Mc Nulty, T., 2009. The immediate life support course: Implementation into an undergraduate nursing programme. Nursing in Critical Care 14, 297-302.

Royal College of Physicians, 2012. National Early Warning Score (NEWS): Standardising the assessement of acute-illness severity in the NHS. Royal College of Physicians, London.

Rudolph, J.W., Simon, R., Dufresne, R.L., Raemer, D.B., 2006. There's no such thing as "nonjudgmental" debriefing: A theory and method for debriefing with good judgment. Simulation in Healthcare 1, 49-55.

Rudolph, J.W., Simon, R., Raemer, D.B., Eppich, W.J., 2008. Debriefing as formative assessment: Closing performance gaps in medical education. Academic Emergency Medicine 15, 1010-1016.

Santiano, N., Young, L., Hillman, K., Parr, M., Jayasinghe, S., Baramy, L.S., Stevenson, J., Heath, T., Chan, C., Claire, M., Hanger, G., 2009. Analysis of medical emergency team calls comparing subjective to "objective" call criteria. Resuscitation 80, 44-49.

Savoldelli, G.L., Naik, V.N., Park, J., Joo, H.S., Chow, R., Hamstra, S.J., 2006. Value of debriefing during simulated crisis management: Oral versus video-assisted oral feedback. Anesthesiology 105, 279-285.

Sawyer, T., Sierocka-Castaneda, A., Chan, D., Berg, B., Lustik, M., Thompson, M., 2012. The effectiveness of video-assisted debriefing versus oral debriefing alone at improving neonatal resuscitation performance: A randomized trial. Simulation in Healthcare: The Journal of The Society for Medical Simulation 7, 213-221.

Schubert, C.R., 2012. Effect of simulation on nursing knowledge and critical thinking in failure to rescue events. Journal of Continuing Education in Nursing 43, 467-471.

Smith, G.B., Osgood, V.M., Crane, S., Group, A.C.D., 2002. ALERT - A multiprofessional training course in the care of the acutely ill adult patient. Resuscitation 52, 281-286.

Smith, G.B., Prytherch, D.R., Schmidt, P.E., Featherstone, P.I., 2008a. Review and performance evaluation of aggregate weighted 'track and trigger' systems. Resuscitation 77, 170-179.

Smith, G.B., Prytherch, D.R., Schmidt, P.E., Featherstone, P.I., Higgins, B., 2008b. A review, and performance evaluation, of single-parameter "track and trigger" systems. Resuscitation 79, 11-21. 
Steinwachs, B., 1992. How to facilitate a debriefing. Simulation \& Gaming 23, 186-195.

Tait, M., Tait, D., Thornton, F., Edwards, M., 2008. Development and evaluation of a critical care e-learning scenario. Nurse Education Today 28, 970-980.

Tanner, C.A., 2006. Thinking like a nurse: A research-based model of clinical judgment in nursing. Journal of Nursing Education 45, 204-211.

Tirkkonen, J., Yla-Mattila, J., Olkkola, K.T., Huhtala, H., Tenhunen, J., Hoppu, S., 2013. Factors associated with delayed activation of medical emergency team and excess mortality: An Utstein-style analysis. Resuscitation 84, 173-178.

Unsworth, J., McKeever, M., Kelleher, M., 2012. Recognition of physical deterioration in patients with mental health problems: the role of simulation in knowledge and skill development. Journal of Psychiatric and Mental Health Nursing 19, 536-545.

Waxman, K.T., 2010. The development of evidence-based clinical simulation scenarios: Guidelines for nurse educators. Journal of Nursing Education 49, 29-35.

Wehbe-Janek, H., Lenzmeier, C.R., Ogden, P.E., Lambden, M.P., Sanford, P., Herrick, J., Song, J., Pliego, J.F., Colbert, C.Y., 2012. Nurses' perceptions of simulation-based interprofessional training program for rapid response and code blue events. Journal of Nursing Care Quality 27, 43-50.

Wickers, M.P., 2010. Establishing the climate for a successful debriefing. Clinical Simulation in Nursing 6, e83-86.

World Health Organization, 2008. Global priorities for patient safety, 1 ed. World Health Organization, Geneva. 